\title{
TRIANGLES, PARAMETERS, MODULUS OF SMOOTHNESS IN NORMED SPACES
}

\section{MARCO BARONTI AND PIER LUIGI PAPINI}

Abstract. Around 15 years ago several authors studied the parameter defined by

$$
A_{2}(X)=\sup \left\{\frac{\|x+y\|+\|x-y\|}{2}: x, y \in S_{X}\right\},
$$

where $S_{X}$ denotes the unit sphere of the real Banach space $X$. In this paper we consider the new family of parameters that generalize $A_{2}(X)$ :

$$
A_{2, p}(X)=\sup \left\{\frac{\|x+y\|+\|x-y\|}{2}: x, y \in X,\|(\|x\|,\|y\|)\|_{p} \leqslant 2^{\frac{1}{p}}\right\}, 1 \leqslant p \leqslant \infty .
$$

In this way, $A_{2, \infty}(X)$ is nothing else than $A_{2}(X)$ and we show how some interesting properties of real Banach spaces can be characterized by using our new constants.

Mathematics subject classification (2010): Primary 46B20; Secondary 46B99.

Keywords and phrases: Parameters, triangles, modulus of smoothness, uniform nonsquareness.

\section{REFERENCES}

[1] J. Alonso And E. Llorens-Fuster, Geometric mean and triangles inscribed in a semicircle in Banach spaces, J. Math. Anal. Appl. 340, 2 (2008), 1271-1283.

[2] M. Baronti, E. CASini And P. L. PAPInI, Triangles inscribed in a semicircle, in Minkowski plane and in normed spaces, J. Math. Anal. Appl. 252, 1 (2000), 124-146.

[3] G. Z. Chelidze, On Nordlander's conjecture in the three-dimensional case, Ark. Mat. 47, 2 (2009), 267-272.

[4] H. CUI AND G. Lu, Hölder means and triangles inscribed in a semicircle in Banach spaces, Filomat 26, 2 (2012), 371-377.

[5] K. Goebel And W. A. Kirk, Topics in metric fixed point theory, Cambridge University Press, Cambridge 1990.

[6] J. Lindenstrauss, On the modulus of smoothness and divergent series in Banach spaces, Michigan Math. J. 10 (1963), 241-252.

[7] P. L. PAPInI, Averaging at any level, Acta Math. Univ. Comenian. (N.S.) 70, 2 (2001), 269-280.

[8] P. L. PAPINI, Constants and symmetries in Banach spaces, Ann. Univ. Mariae Curie-Skłodowska Sect. A 56 (2002), 65-76.

[9] Z. D. Ren, On the Baronti constants of Orlicz function spaces, Rend. Circolo Mat. Palermo (2) 59, 3 (2010), 483-497.

[10] Y. Takahashi And M. Kato, On the inequality $C_{N J} \leqslant J(X)$, in: Banach and function spaces III, M. Kato, L. Maligranda and T. Suzuki eds., Yokohama Publ. 2011, 305-316.

[11] Y. TAKAhASHI AND M. KATO, On a new geometric constant related to the modulus of smoothness of a Banach space, Acta Math. Sinica 30, 9 (2014), 1526-1538.

[12] F. WAng, On the James and von Neumann-Jordan constants in Banach spaces, Proc. Amer. Math. Soc. 138, 2 (2010), 695-701. 
[13] F. H. WAng And B. PAng, Some inequalities concerning the James constant in Banach spaces, J. Math. Anal. Appl. 353, 1 (2009), 305-310.

[14] F. H. WANG AND C. S. YANG, Absolute normalized norms and the Baronti constant (Chinese), Acta Math. Sinica (Chin. Ser.) 50, 4 (2007), 745-750.

[15] H. Zuo And M. YAng, Generalized Baronti constant and normal structure, J. Math. Sci. Adv. Appl. 4, 2 (2010), 255-263. 